pupil was dilated a small coloboma of the lens was discovered. There appeared to be a small opacity in the lower part of the lens.

The slit-lamp examination with the broad beam showed that the mass had the texture and colour of ordinary uveal tissue, and that there was no vascularization. It merged with the ciliary body without any abrupt edge, and had no irregularity of surface that might be present in a new growth.

The vitreous was perfectly normal showing the usual films without any trace of infiltration with cells or larger particles.

When examined with the narrow beam in optical section, it was seen that the white area seen by focal illumination on the surface of the mass was really a flocculent filamentous deposit on the back of the lens. It extended downwards and was lost in the region of the coloboma.

The lens itself, except in the colobomatous area was perfectly clear, and showed the usual sutures and zones of discontinuity.

I came to the conclusion that the mass was due to an abnormal development of the ciliary body in the lower sector of the eye, probably a fusion of several processes, and that there could be no question of sarcomatous growth. Apart from the fact that the lens was obviously implicated in the abnormal picture, the absence of vascularization, the normal aspect of the vitreous, and the normal tension as estimated with the Schiötz tonometer, were evidence against tumour formation.

Mrs. D. has now been under observation for six months and no change has taken place in the eye.

\title{
CONSERVATION OF EYEDROPS
}

\author{
BY \\ DR. KLEIN MiKLós \\ FROM THE DEPARTMENT OF OPHTHALMOLOGY, \\ UNIVERSITY PÉCS, HUNGARY, PROFESSOR DR. K. ALBRICH
}

THE sterility of eyedrops is very important because they are used after operations which open the globe and also after perforating. injuries, when it is possible for micro-organisms to be carried with the drops into the internal part of the bulb, and thus cause dangerous infections.

First, we had to examine whether the eyedrops are infected or not. It is well known that most eyedrops, chiefly the alkaloids, become after more or less time opalescent, and, in these there 
appear white filaments. When we inoculate from such a fluid an agar-agar plate, after 10-12 hours we find it amply furred with different colonies of micro-organisms.

Apart from the bactericidal remedies we succeeded in breeding micro-organisms from all the eyedrops in general use : atropine, scopolamine, eserine, pilocarpine, holocaine, homatropine, and zinc-sulphate.

The cultures grew bac. myentericus, bac. prodigiosus, and other non-determined chromogen saprophytes; also staphylococcus albus and citreus. Besides these we found some kinds of fungi the identification of which is now in progress.

The infection of the eyedrops occurs by touching the patient's face or conjunctiva with the glass dropper. The air infection also plays a part. So we presumed that the bacterial infection varies in different countries and therefore we gave up the exact identification. It is important that we found in the infected eyedrops staphylococcus which can cause eye infections.

We determined the duration of sterility of eyedrops. When we opened the bottle several times daily, i.e., only air infection, we find almost all fresh, sterile prepared eyedrops infected before 48 hours. Of course, in these cases the liquid seemed perfectly clear and only on nutrient media we proved the presence of infection. Consequently, the infection of eyedrops is not recognized by the naked eye.

From the above it is evident that the conservation of eyedrops is very important. For this we have many possibilities. The daily sterilizing is very tiresome and the boiling of the easily decomposable alkaloids spoils them. It is recommended also to add 1 : 10,000 mercury-oxycyanate to the eyedrops. We object to this practice. Many conjunctival sacs do not tolerate this treatment and the mercury salt has a reaction against the alkaloids and can decompose them.

The cover over the bottle does not protect against the air infection because when the drops are used the glass is open.

The conservating substances used in the laboratory such as phenol, salicylic acid, benzoic acid, and thymol cannot be used, partly because of the caustic effect, and partly because of their disagreeable odour. A long time ago the conservating effects of resin benzoic were discovered. We knew too that its effect does not depend on the content of benzoic acid, because the resin, probably due to its ester content, conserves better. Sabalitschka drew attention to the ester of the benzoic acid, which has a greater advantage in comparison with the other conservating substances. They are neutral, have no smell, and do not dye. They are soluble with difficulty in water. We know that the dividing co-efficient lipoid: water also has a rôle in the process of disinfection. The 
following figures taken out of Sabalitschka's work show that the dividing co-efficient becomes a high value in the different esters. This table also shows the hindering and destroying effects on cultures of the staphylococcus. All the comparisons are made to phenol, the value of which is taken as 1 .

\section{TABLE I. - SABALITSChKa}

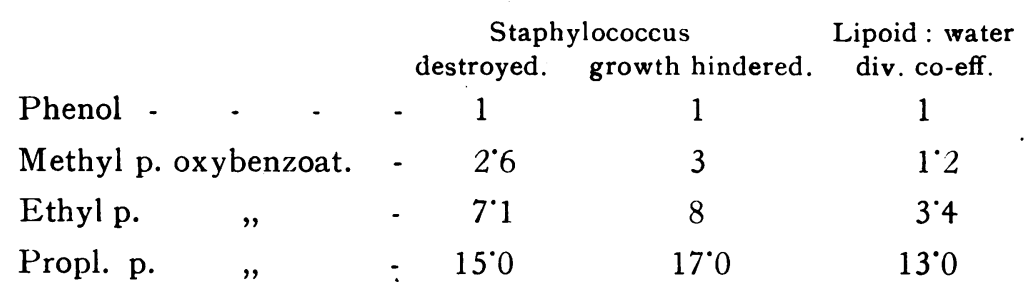

The small quantities which are carried with the eyedrops into the culture are from toxic point of view not taken in account. Schübel and Manger established by experiments on dogs and rabbits, that per os $2 \mathrm{gr}$. of the methylester for every kg. body weight is toxic, and $3 \mathrm{gr}$. per $\mathrm{kg}$. body weight is lethal; from the ethylester 4 or $5 \mathrm{gr}$. per $\mathrm{kg}$. body weight is toxic or lethal; from the propylester $3-4$ or $6 \mathrm{gr}$. per $\mathrm{kg}$. body weight toxic or lethal. Accumulation does not follow. The esters are less toxic than the para-oxybenzoic acid itself.

Since the infected eyedrops may contain bacteria which have a rôle in the pathology of the eye, it seemed important to find out a method of conservation for eyedrops so that their effect remains unchanged. We should conserve eyedrops because they contain expensive alkaloids and at large hospitals economy is important. Finally, by means of conservation the physician is released from the duties of controlling the sterility of eyedrops.

We tried for eyedrop conservation the use of the esters of benzoic acid because as we mentioned above they have many advantages.

In our researches to conservate eyedrops, we experimented with the three esters and their compounds which are soluble in water. The method was the following. We added the above-mentioned substances to agar-agar in different proportions. The nutrient media thus prepared, we inoculated with micro-organisms taken from infected eyedrops. In order to put in all nutrient media an equal quantity of micro-organisms we made first a uniform emulsion in the mortar and we placed the micro-organisms in all test tubes with the same platinum hook. Besides this we made our investigations with fluid nutrient media and with blood-agar plates. The 
micro-organisms which we used were derived from different eyedrops and from an orbito-phlegmon pus, consisting of a mixed culture of streptococci, staphylococci, and bacillus coli.

The results are as follows :-

\section{TABLE II}

\begin{tabular}{|c|c|c|c|c|c|c|c|c|}
\hline 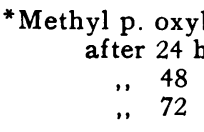 & $\begin{array}{l}\text { benze } \\
\text { lours } \\
\text { ", } \\
\text { ", }\end{array}$ & $\begin{array}{l}\text { oate } \\
- \\
-\end{array}$ & $\begin{array}{l}- \\
- \\
-\end{array}$ & - & $\begin{array}{c}0.1 \% \\
+++ \\
++++ \\
++++\end{array}$ & $\begin{array}{l}0.2 \% \\
- \\
- \\
-\end{array}$ & $\begin{array}{l}\text { Control } \\
++++ \\
++++ \\
++++\end{array}$ & \\
\hline $\begin{array}{r}{ }^{*} \text { Methyl p. oxy } \\
\text { after } 24 \\
,, \quad 48\end{array}$ & $\begin{array}{l}\text { penzc } \\
\text { lours } \\
\text { ", }\end{array}$ & oate & $\begin{array}{l}\text { natr. } \\
- \\
-\end{array}$ & - & $\begin{array}{c}0.1 \% \\
++++ \\
++++\end{array}$ & $\begin{array}{l}0.2 \% \\
+ \\
++\end{array}$ & $\begin{array}{l}\text { Control } \\
++++ \\
++++\end{array}$ & \\
\hline $\begin{array}{r}{ }^{*} \text { Ethyl p. oxybe } \\
\text { after } 24 \\
, \quad 48 \\
, \quad 72\end{array}$ & $\begin{array}{l}\text { nzoa } \\
\text { lours } \\
",\end{array}$ & $\begin{array}{l}\text { ate } \\
- \\
-\end{array}$ & $\begin{array}{l}- \\
- \\
-\end{array}$ & $\begin{array}{l}- \\
- \\
-\end{array}$ & $\begin{array}{l}0.075 \% \\
++++\end{array}$ & $\begin{array}{l}\frac{0.1}{+} \% \\
+ \\
++\end{array}$ & $\begin{array}{l}0.15 \% \\
- \\
- \\
-\end{array}$ & $\begin{array}{l}\text { Control } \\
++++ \\
++++ \\
++++\end{array}$ \\
\hline $\begin{array}{r}{ }^{*} \text { Ethyl p. oxybe } \\
\text { after } 24 \text { b } \\
, " 48 \\
,, \quad 72\end{array}$ & $\begin{array}{l}\text { nzoa } \\
\text { lours } \\
\text { ", }\end{array}$ & - & $\begin{array}{l}\text { tr. } \\
- \\
-\end{array}$ & - & $\begin{array}{l}0.1 \% \\
++ \\
+++ \\
+++\end{array}$ & $\begin{array}{l}0.15 \% \\
+ \\
++ \\
++\end{array}$ & $\begin{array}{l}0.2 \% \\
- \\
- \\
-\end{array}$ & $\begin{array}{l}\text { Control } \\
++++ \\
++++ \\
++++\end{array}$ \\
\hline $\begin{array}{r}{ }^{*} \text { Propyl p. oxyl } \\
\text { after } 24 \\
\text { " } 48 \\
, \quad 72\end{array}$ & $\begin{array}{l}\text { enzo } \\
\text { ours } \\
\text { " }\end{array}$ & $\begin{array}{l}\text { oate } \\
\text { s } \\
-\end{array}$ & $\begin{array}{l}- \\
- \\
-\end{array}$ & 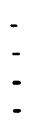 & $\begin{array}{l}0.03 \% \\
++ \\
+++ \\
+++\end{array}$ & $\begin{array}{l}0.04 \% \\
+ \\
+ \\
+\end{array}$ & $\begin{array}{l}0.05 \% \\
- \\
- \\
-\end{array}$ & $\begin{array}{l}\text { Control } \\
++++ \\
++++ \\
++++\end{array}$ \\
\hline 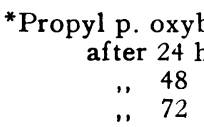 & $\begin{array}{l}\text { enzo } \\
\text { lours } \\
\text { ", }\end{array}$ & $\begin{array}{l}\text { oate } \\
\text { - } \\
-\end{array}$ & $\begin{array}{l}\text { latr. } \\
- \\
- \\
-\end{array}$ & - & $\begin{array}{l}0.05 \% \\
++ \\
+++ \\
+++\end{array}$ & $\begin{array}{l}0.06 \% \\
- \\
+\end{array}$ & $\begin{array}{l}0.075 \% \\
- \\
- \\
-\end{array}$ & $\begin{array}{l}\text { Control } \\
++++ \\
++++ \\
++++\end{array}$ \\
\hline
\end{tabular}

The results on fluid nutrient media are a little better than those on solid ones. To control the growths on a fluid medium is not so easy and it is far better to compare on a solid medium, especially when there are only one or two colonies. Therefore, the majority of examinations were done on solid media. The figures do not show the average, but the worst values which occurred. In the propyl esters case the micro-organisms were already hindered in growing by 0.04 per cent. and with the natr. compound by 0.05 per cent. concentration. Only in two cases we found a tiny growth at the concentration mentioned above : in one case by mixed streptostaphylococcus inoculation. Of course, the hindering effect depends also on the virulence and not only on the concentration of the disinfectant applied.

We found that all three blends are able to conserve. In the case of methylester the effective concentration is at $0 * 2$ per cent.; ethylester 0.15 ; and propylester 0.05 per cent.; with the natr.

* Manufacturer: Ful. Penner, Berlin-Schöneberg. 
compounds which are soluble in water the effecting concentration is about $1 / 5$ more. It seems reasonable to use the propyl p.oxybenzoate for the conservation of eyedrops because the necessary concentration is with this substance the least, and its toxic effect is also the smallest.

The micro-organisms which are smeared on agar plates and are hindered in growing, die after some time. Our results concerning this are as follows: Micro-organisms cultured on prepared agar plates die in 6-10 days. The method was as follows. With the above-mentioned substances prepared agar-tubes were inoculated and the tubes were washed at various times with sterile bouillon and this bouillon was placed in a thermostat. By applying fluid nutrient media the method was simpler because at various times we inoculated a drop into sterile bouillon. In the fluid medium the staphylococcus perishes at the concentration $0 \cdot 1$ per cent. propyl p.oxybenzoate natr. in less than 48 hours.

We do not forget that during the investigations the microorganisms are on a nutrient medium, i.e., among favourable life conditions and as they are only on the surface of the agar plate they cannot be in contact with the disinfectant substance. In the eyedrops the conditions are worse, because they do not have the best medium for growth for in the fluid they are in permanent and direct contact with the disinfectant.

At the practical application we found that the water soluble natr. compound of the propyl ester gives with the holocaine and zincsulphate an opalescent solution, and the eserine becomes red in a few hours. Therefore, we cannot apply it. The pure ester is good for the purpose of conserving eyedrops. It is advisable to prepare first an alcohol stock solution 1: 4 because the pure ester is very difficult to dissolve in water. The dilution we make from this stock solution. In preparing the necessary solution, the water must be kept in motion and the stock solution must be added only in drops. If it precipitates the whole must be boiled, and the solution remains clear after cooling. The boiling is good because by means of it the small quantity of alcohol of the stock solution evaporates. The water thus prepared is ready for eyedrops.

The propyl p.oxybenzoate we applied in 0.05 per cent. concentration. The eyedrops thus prepared are durable and they remain sterile. All substances used in eye treatment are easily soluble with a 0.05 per cent. propyl p.oxybenzoate solution. A further advantage is that the eserine does not become red, even after a long time.

First we tried on rabbits' eyes and later on patients. We can determine that with the above-mentioned substance, prepared eyedrops do not irritate the conjunctiva. 


\section{Conclusions}

We tried different esters of the para-oxybenzoic acid in order to conserve eyedrops and found that the most suitable of these is the propylester in 0.05 per cent. concentration. The eyedrops thus prepared hinder entirely the growth of the micro-organisms and by the mild bactericidal effect those which enter the eyedrops die.

The eyes tolerate these prepared eyedrops well.

This method of conservation is recommended, because by it the physician does not have trouble in keeping the eyedrops pure.

Also from an economical point of view it is necessary to conserve eyedrops, because many of the alkaloids which are used in it are expensive.

\section{LITERATURE}

Th. Sabalitschka.-Arch. de Pharmacie, Vol. XXIX, p. 272, 1929.

\section{ANNOTATION \\ International Illumination Congress, I93I}

During September, there was held in Great Britain an International Illumination Congress. This Congress forms an adjunct to the meetings of the International Commission on Illumination. This latter body was originally founded in 1900 as the International Commission on Photometry and was changed in 1913 to its present form. It is in essence a co-ordinating body, being composed of delegates from National Illumination Committees which exist in most civilized countries. Recently, the meetings of this Commission have been preceded by a Congress to which everybody interested in illumination could come.

This particular Congress has attained some notoriety owing to the flood-lighting, in honour of the Congress, of some of the public buildings in London and elsewhere. It is not necessary to say very much about this feature. Some of the illumination was merely a glare. Occasionally, it rendered visible architectural features which are not ordinarily observed and the flood-lighting of some of the flower beds in St. James's Park was interesting, as showing what can be done. It is only fair to say that no charge fell upon the public authorities for all this expenditure of energy.

The Congress assembled in London on September 1, and on the 3 rd began a tour through the principal industrial centres of Britain, 